\section{ONCOLOGY; EPIDEMIOLOGY}

\section{Alcohol drinking in never users of tobacco, cigarette smoking in never drinkers and the risk of head and neck cancer: pooled analysis in the international head and neck cancer epidemiology consortium}

Hashiba M, Brennan P et al. J Nat/ Cancer Inst 2007; 99: 777-789

Smoking without drinking had a significant effect, but there was a threshold for alcohol's effect.

Combined smoking and drinking causes at least $3 / 4$ of head and neck cancers (HNCs) and there is a strong synergistic effect, but the separate effects of the individual factors are difficult to elicit. The aetiology of HNCs in never-smoking patients is unclear. In this study, results were combined from 15 case-control studies comparing a total of 10,244 HNC patients with 15,227 controls.

Tobacco was never used by 1,072 cases and 5,775 controls, and alcohol was never used by 1,598 cases and 4,051 controls. In never-drinkers, the OR for HNC in all smokers was 2.13 (CI: 1.5-3.0), with a dose-response relationship. In never-smokers, there was a risk of HNC only for $>4.5$ units per day of alcohol, with an OR of 2.04 (1.3-3.2). Thus $24 \%$ of HNC were attributable to tobacco in never-drinkers, but 7\% to alcohol in neversmokers, assuming causality.

DOI: $10.1038 /$ bdj.2007.638

\section{PERIODONTOLOGY; METABOLIC MEDICINE}

\section{Diabetes mellitus promotes periodontal destruction in children}

Lalla E, Cheng B et al. J Clin Periodonto/ 2007; 34: 294-298

This study reports significantly increased attachment loss in young diabetic children.

Diabetes mellitus significantly increases periodontal attachment loss, and recent studies have suggested this may begin as early as 6-11 yrs of age. This study compared periodontal conditions in 350 diabetics and 350 controls aged 6-18 yrs. The majority were of Hispanic ethnicity, but significantly fewer of them were diabetics.

Mean $\mathrm{HbA1c}$ was $8.5 \%$ in diabetics, of whom 95\% took insulin. Mean visible plaque was 30\% in diabetics, and 24\% in controls. Respective mean scores for BOP were 19\% and 14\%, and for attachment loss (AL), 1.2 and $0.7 \mathrm{~mm}$. Logistic regression analysis gave significant ORs for sites with AL $>2 \mathrm{~mm}$ in more diabetic subjects aged 6-11 yrs and in those aged 12-18.

\section{ORTHODONTICS; RESPIRATORY PHYSIOLOGY}

\section{Evaluation of cervical posture following palatal expansion: a 12-month follow-up controlled study}

\author{
Tecco S, Caputi S et al. Eur J Orthod 2007; 29: 45-51
}

Rapid palatal expansion (RPE) may change cervical neuromuscular behaviour.

Airway function influences facial morphology and head posture, but there is limited evidence on whether treating the former can change the latter. In this study, $45+$ children aged 8-15 yrs and requiring RPE were randomised to treatment immediately or 14 months later (controls). RPE proceeded at about $0.2 \mathrm{~mm} /$ day and when completed, the appliance was used as a retainer for 4-7 months.

The mean angle between the upper and lower cervical spine increased from $9.8^{\circ}$ to $11^{\circ}$ in the treatment group over $1 \mathrm{yr}$ $(P<0.05)$; respective control means were $9.6^{\circ}$ and $9.0^{\circ}(\mathrm{NS})$. In the test group there were also changes in cervical, craniofacial and craniocervical inclinations; there were no significant changes in controls. There was also a correlation between size of the nasopharyngeal airway and craniocervical angulation $(\mathrm{r}=-0.61 ; P<0.05)$.

DOI: $10.1038 /$ bdj.2007.639

\section{PREVENTIVE DENTISTRY; COST-BENEFIT ANALYSIS}

\section{The value of caries preventive care among} 19-year olds using the contingent valuation method within a cost-benefit approach

Oscarson N, Lindholm L et al. Community Dent Oral Epidemio/ 2007; 35: 109-117

Using this approach, preventive benefits exceeded their cost.

One way of estimating the value of a health benefit is by the willingness-to-pay (WTP) of the individuals concerned. In this Swedish study, 82 subjects aged 19 yrs with high caries experience were compared with 52 who had no caries experience. Subjects were asked whether they would pay $£ 5.60$ per month to decrease their risk of a filling by $50 \%$ for the next $2 \mathrm{yrs}$, and also their maximum WTP.

The high risk group mean WTP was £104 p.a., and the low risk, £80. When compared with figures for actual treatment costs from a previous 4-yr study, the annual net social benefit was estimated at $£ 77$ and $£ 53$ respectively from the perspective of dental health care (solely treatment cost), and $£ 62$ and $£ 39$ from a societal perspective, where travel, time and other expenses were included.

DOI: $10.1038 /$ bdj.2007.641 